\title{
Visualization of bronchoalveolar fistula as the presenting sign of lung cancer
}

Francesco Givigliano, MD, Antonello La Rocca, MD, Michele Salati, MD, Luigi Busiello, MD, Carmine La Manna, MD, Francesco Scognamiglio, MD, and Gaetano Rocco, MD, FRCS (Ed), FECTS, Naples, Italy

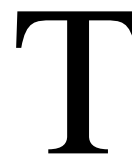

he incidence of pneumothorax resulting from bronchoalveolar fistula complicating primary or secondary lung cancer ranges between $1 \%$ and $4 \% .^{1}$ Because of the rarity of this condition ( 4 cases out of 663 admissions for lung cancer $[0.4 \%$ ] during a 2-year period in our institution), preventing the accumulation of large numbered series, and the anecdotal nature of the reported cases, it has not been possible to investigate the pathophysiology and codify the possible therapeutic pathways indicated in the management of this particular type of pneumothorax.

\section{Clinical Summary}

An asymptomatic 52-year-old woman was referred to our attention for the detection on a chest radiogram of a total collapse of the right lung. After chest drain insertion, a computed tomographic scan showed a $5-\mathrm{cm}$ right upper lesion with no obvious mediastinal nodal enlargement. The surgical approach entailed a right video-assisted thoracoscopy to rule out pleural dissemination; a subpleural tear

From the Division of Thoracic Surgery, National Cancer Institute, Pascale Foundation, Naples, Italy.

Received for publication Aug 22, 2007; accepted for publication Oct 17, 2007.

Address for reprints: Gaetano Rocco, MD, FRCS (Ed), FECTS, Division of Thoracic Surgery, National Cancer Institute, Pascale Foundation, Via M. Semmola, 81, 80131, Naples, Italy (E-mail: Gaetano.Rocco@btopenworld. com).

J Thorac Cardiovasc Surg 2008;135:704-5

$0022-5223 / \$ 34.00$

Copyright $\odot 2008$ by The American Association for Thoracic Surgery doi:10.1016/j.jtcvs.2007.10.047 in the pulmonary mass in the upper lobe was identified (Figure 1). During the same session, a right upper lobectomy with complete mediastinal nodal dissection was performed via a right totally musclesparing hybrid (video-assisted/open) approach. The final pathologic report showed a pT2 N0 adenocarcinoma.

Both non-small cell and small-cell lung cancers have been associated with pneumothorax either as a presenting sign or as a treatment-related complication. When primary lung cancer manifests itself in young patients with a spontaneous pneumothorax, the prognostic outlook is considered acceptable because an early diagnosis often leads to early treatment. ${ }^{2}$ Conversely, if the pneumothorax appears late in the course of the disease, it generally portends an ominous prognosis. ${ }^{3,4}$

Extrathoracic malignant tumors can equally metastasize to the lung and virtually all histotypes have been associated with the onset of a pneumothorax. The etiopathogenesis of the pneumothorax can be multifactorial, ${ }^{1,2}$ and the same side as the cancer or the contralateral side can be affected depending on whether the actual tumor is the direct cause of the pneumothorax.

The treatment of this condition depends on the patient's age and performance status, cardiorespiratory functional reserve, and life expectancy. The ideal situation is to radically treat the cancer by a formal resection or by lung volume reduction surgery as per recent reports. ${ }^{3-5}$ However, when this is not feasible, alternative management aimed primarily at achieving pleurodesis ${ }^{3}$ should be considered after an adequate, but not prolonged, observation period (up to 2 weeks).

\section{References}

1. Srinivas S, Varadhachary G. Spontaneous pneumothorax in malignancy: a case report and review of the literature. Ann Oncol. 2000;11:887-9.
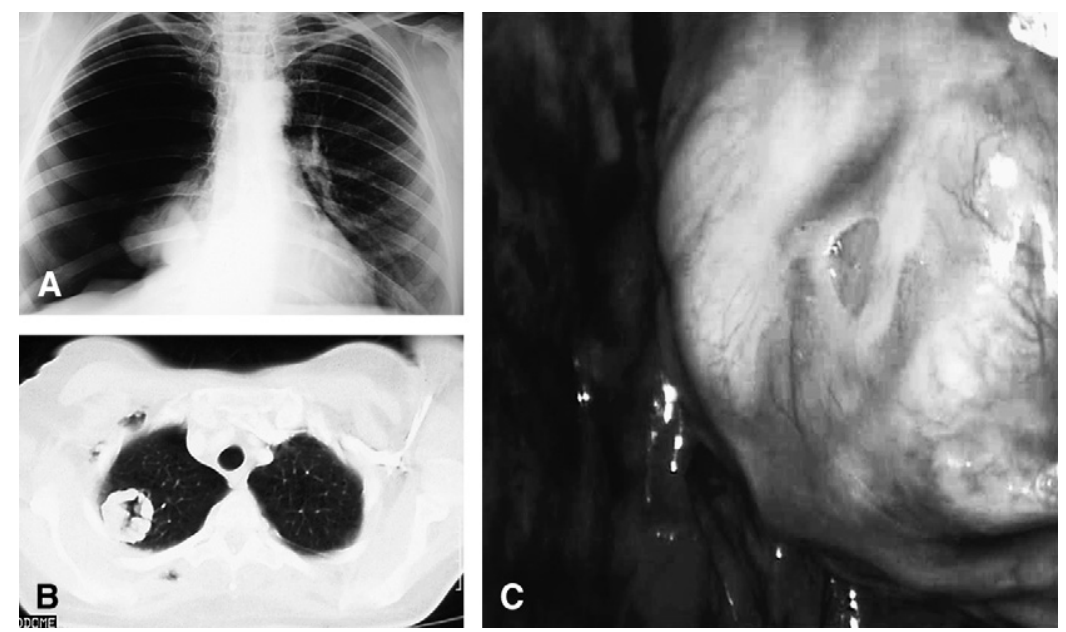

Figure 1. Radiologic evidence of the total collapse of the right lung (A), computed tomographic demonstration of the right upper lobe cancer (B), and the thoracoscopic view of the subpleural parenchymal tear (C). 
2. Pohl D, Herse B, Criee CP, Dalichau H. Spontaneous pneumothorax as the initial symptom of bronchial cancer. Pneumologie. 1993;47: 69-72.

3. Suter M, Bettschart V, Vandoni RE, Cuttat JF. Thoracoscopic pleurodesis for prolonged (or intractable) air leak after lung resection. Eur J Cardiothorac Surg. 1997;12:160-1.
4. Mukaida T, Andou A, Date H, Aoe M, Shimizu N. Thoracoscopic operation for secondary pneumothorax under local and epidural anesthesia in high-risk patients. Ann Thorac Surg. 1998;65:924-6.

5. Nakamura H, Takamori S, Miwa K, Fukunaga M, Maeshiro K, Matsuo T, et al. Rapid-growth lung cancer associated with a pulmonary giant bulla: a case report. Kurume Med J. 2003;50:147-50.

\title{
Incidence of venous thromboembolism in patients undergoing thoracotomy for lung cancer
}

\author{
Francesco Dentali, MD, ${ }^{a}$ Alessandra Malato, MD, ${ }^{\mathrm{b}}$ Walter Ageno, MD, ${ }^{\mathrm{a}}$ Andrea Imperatori, MD, ${ }^{\mathrm{c}}$ Massimo Cajozzo, MD, \\ Nicola Rotolo, MD, ${ }^{\mathrm{c}}$ James Douketis, MD, ${ }^{\mathrm{e}}$ Sergio Siragusa, MD, ${ }^{\mathrm{b}}$ and Mark Crowther, MD, ${ }^{\mathrm{e}}$ Varese and Palermo, Italy, \\ and Hamilton, Ontario, Canada
}

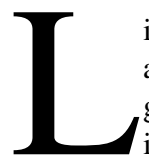
imited information exists on the incidence of symptomatic venous thromboembolism (VTE) in patients undergoing chest surgery for lung cancer. Several factors increase the thromboembolic risk in patients undergoing surgery for lung cancer: the intrinsic procoagulant effect of cancer, extensive surgical intervention, dependent limb position in the operating room, and vessel injury consequent to the operation. Furthermore, these patients might be especially vulnerable to pulmonary embolism (PE) because of the loss of lung tissue and the presence of chronic obstructive pulmonary disease and cardiovascular diseases caused by smoking. ${ }^{1}$

Older studies found a very high incidence of thromboembolic events in these patients. . $^{2,3}$

However, the risk of thromboembolic complications in lung cancer surgery might have changed over the last years. Extensive use of antithrombotic prophylaxis, improvement in surgical techniques and perioperative care, and more prompt mobilization might have reduced the risk of VTE.

Therefore, the aim of our study was to provide up-to-date reliable data on the incidence of venous thromboembolic complication in a large cohort of patients undergoing chest surgery for malignant

From the Department of Clinical Medicine, ${ }^{\text {a }}$ Insubria University, Varese, Italy; the Thrombosis/Haemostasis and Haematology Unit, ${ }^{\text {b }}$ University Hospital of Palermo, Palermo, Italy; the Center for Thoracic Surgery, ${ }^{c}$ University of Insubria, Varese, Italy; the Department of Surgery, Division of General and Thoracic Surgery, ${ }^{\mathrm{d}}$ University of Palermo, Palermo, Italy; and the Department of Medicine, ${ }^{\mathrm{e}}$ McMaster University, Hamilton, Ontario, Canada.

Mark Crowther reports consulting and lecture fees from Leo Pharma and grant support from Leo Laboratories. Leo Pharma produces heparin.

Received for publication Aug 23, 2007; accepted for publication Oct 2, 2007.

Address for reprints: Francesco Dentali, MD, U.O. Medicina I, Ospedale di Circolo, Viale Borri 57, 21100 Varese, Italy (E-mail: fdentali@libero.it).

J Thorac Cardiovasc Surg 2008;135:705-6

$0022-5223 / \$ 34.00$

Copyright (C) 2008 by The American Association for Thoracic Surgery doi:10.1016/j.jtcvs.2007.10.036 lung disease. Furthermore, the raw mortality rate and the mortality rate related to $\mathrm{PE}$ were evaluated.

\section{Clinical Summary}

We performed a chart review of all patients undergoing chest surgery for malignant lung disease who were operated on between January 1, 2002, and December 1, 2004, at St Joseph's Hospital, Hamilton, Ontario, Canada, and between January 1, 2005, and December 1, 2006, at 2 university hospitals in Italy (Varese and Palermo). The charts of eligible patients were reviewed for baseline clinical characteristics, including sex, age, prior history of cardiovascular disease, and use and type of antithrombotic prophylaxis. Perioperative mortality and all objectively confirmed venous thromboembolic events were noted. Notes of follow-up ambulatory surgical visits were also reviewed within 4 weeks of hospital discharge after surgical intervention to ensure that cases of VTE occurring after discharge were not missed. The study protocol was approved by the regional institutional review boards.

Baseline characteristics are summarized in Table 1. Six hundred ninety-three patients were identified (mean age, 66.7 years; range, 23-90 years); $418(60.6 \%)$ patients were male, and the median length of hospitalization was 7 days. One hundred fifty-five $(22.5 \%)$ patients had a history of cardiovascular disease. Almost $90 \%$ of patients attended at least 1 follow-up ambulatory surgical visit after discharge. Postoperative antithrombotic prophylaxis with unfractionated heparin at a dose of $5000 \mathrm{U}$ twice daily was used in $464(67.2 \%)$ patients, and low-molecular-weight heparin was used in $153(22.2 \%)$ patients. Only $16(2.3 \%)$ patients did not receive antithrombotic prophylaxis. Five hundred seven $(73.5 \%)$ patients had primary lung cancer, and 183 had secondary malignant lung cancer. Lung primary adenocarcinoma, epidermoid carcinoma, and anaplastic cancer were the most common cancer histologies. Ninety-three $(13.5 \%)$ patients underwent pneumectomy, and 597 $(86.5 \%)$ underwent lobectomy or wedge resection.

There were $12(1.7 \%)$ venous thromboembolic complications, of which 9 (1.3\%) were PEs. All these complications occurred while patients were receiving antithrombotic prophylaxis with unfractionated or low-molecular-weight heparin. Twenty-one (3.0\%) patients died during hospitalization. However, mortality could be attributed 